\title{
Characteristics of L-PRP preparations for treating Achilles Tendon Rupture within the PATH-2 study
}

Paul Harrison, ${ }^{1}$ Marie Didembourg, ${ }^{1}$ Alexander Wood, ${ }^{1}$ Amarpreet Devi, ${ }^{1}$ Robert Dinsdale, ${ }^{1}$ Jon Hazeldine, ${ }^{1}$ Joseph Alsousou, ${ }^{2}$ David J Keene, ${ }^{2}$ Philippa Hulley, ${ }^{3}$ Susan Wagland, ${ }^{2}$ Scott Parsons, ${ }^{3}$ Jacqueline Thompson, ${ }^{2}$ Christopher Byrne, ${ }^{4}$ Michael Maia Schlïssel, ${ }^{5}$ Heather O'Connor, ${ }^{6}$ Susan J Dutton, ${ }^{6}$ Sarah E Lamb, ${ }^{2,7}$ and Keith Willett ${ }^{2}$ on behalf of the PATH-2 study group.

${ }^{1}$ Institute of Inflammation and Ageing, College of Medical and Dental Sciences, University of Birmingham Medical School, Birmingham, UK. ${ }^{2}$ Kadoorie Centre for Critical Care Research, John Radcliffe Hospital, Nuffield Department of Orthopaedics, Rheumatology and Musculoskeletal Sciences, University of Oxford, Oxford, UK. ${ }^{3}$ Botnar Research Centre, Nuffield Department of Orthopaedics, Rheumatology and Musculoskeletal Sciences, University of Oxford, Oxford, UK. ${ }^{4}$ Sport and Health Sciences, College of Life and Environmental Sciences, University of Exeter, UK. ${ }^{5}$ The EQUATOR Network, UK Centre, Oxford, UK. ${ }^{6}$ Oxford Clinical Trials Research Unit, Centre for Statistics in Medicine, Nuffield Departments of Orthopaedics, Rheumatology and Musculoskeletal Sciences, University of Oxford, Oxford. UK. ${ }^{7}$ Warwick Clinical Trials Unit, University of Warwick, UK.

Corresponding Author - p.harrison.1@bham.ac.uk

Keywords: platelet rich plasma, Achilles, tendon, rupture 


\begin{abstract}
Platelet-rich plasma (PRP) is an autologous preparation that has been claimed to improve healing and mechanobiological properties of tendons both in vitro and in vivo. In this sub-study from the PATH-2 (PRP in Achilles Tendon Healing-2) trial, we report the cellular and growth factor content and quality of the Leukocyte-rich PRP (L-PRP) $(\mathrm{N}=103)$ prepared using a standardised commercial preparation method across 19 different UK centres. Baseline whole blood cell counts (red cells, leukocyte and platelets) demonstrated that the two groups were well matched. L-PRP analysis gave a mean platelet count of $852.6 \times 10^{9} / \mathrm{L}$ (SD 438.96), a mean leukocyte cell count of $15.13 \times 10^{9} / \mathrm{L}$ (SD 10.28) and a mean red blood cell count of $0.91 \mathrm{x}$ $10^{12} / \mathrm{L}$ (SD 1.49). The activation status of the L-PRP gave either low or high expression levels of the degranulation marker CD62p before and after ex-vivo platelet activation respectively. TGF- $\beta$, VEGF, PDGF, IGF and FGFb mean concentrations were $131.92 \mathrm{ng} / \mathrm{ml}, 0.98 \mathrm{ng} / \mathrm{ml}$, $55.34 \mathrm{ng} / \mathrm{ml}, 78.2 \mathrm{ng} / \mathrm{ml}$ and $111.0 \mathrm{pg} / \mathrm{ml}$ respectively with expected correlations with both platelet and leukocyte counts. While PATH-2 results demonstrated that there was no evidence L-PRP is effective for improving clinical outcomes at 24 weeks after Achilles tendon rupture, our findings support that the majority of L-PRP properties were within the method specification and performance.
\end{abstract}




\section{Introduction}

Platelet-Rich Plasma (PRP), an autologous derivative of whole blood that contains a supraphysiological concentration of platelets, has gained increasing attention in both the scientific literature and the wider media for its potential application as a regenerative adjunct therapy [15]. Autologous platelet preparations are therefore increasingly being used in many areas of regenerative medicine [6]. Despite recent efforts to improve standardisation, there are few properly conducted randomised clinical trials and the preparation, content and definitions of many platelet preparations are generally poorly defined or controlled for [7]. To further complicate this field the many commercial devices available for preparing sterile preparations of autologous PRP for potential use in regenerative medicine employ different production methods $[3,4,8]$. The resulting PRP products not only exhibit varying concentrations and purity of platelets within plasma but may sometimes also contain leukocytes and erythrocytes [9]. PRP may also be activated prior to clinical use and some products can therefore contain fibrin $[10,11]$. Thus the lack of standardization and known heterogeneity of PRP preparations not only results in variations in cellular and growth factor content but will have potential impact on clinical outcomes. Measuring the cellular and bioactive factor content is therefore essential to understand the variables associated with the potential biological activity and efficacy of PRP. A number of classification systems of PRP preparations have not only improved standardization but have also significantly helped in the comparisons of the impact of cellular and growth factor contents on clinical outcomes [7, 12-17]. The Achilles tendon is the most commonly injured tendon in the human body, accounting for $20 \%$ of all tendon ruptures with an incidence of 11,000 per year in the UK [18, 19]. Therefore, novel therapies involving biological adjuncts including PRP are now being explored in an attempt to diminish the degree and duration of morbidity [20]. Although our pilot study (PATH-1, platelets in Achilles tendon healing) implied efficacy of a leukocyte-rich PRP (L-PRP) preparation, the study was underpowered, and too small to determine whether any PRP preparation variables were associated with efficacy of ATR healing [21]. The PATH-2 study randomised 230 participants to receive a single injection of either autologous L-PRP $(\mathrm{N}=114)$ or placebo in the form of a dry needle injection $(\mathrm{N}=116)$ [22]. As 103 of the 114 participants received L-PRP this also provided an opportunity to study the variation within cellular and bioactive components within the PRP and to determine the performance of a single device (Magellan device, Arteriocyte 
Medical Systems) to prepare an autologous sterile product for ATR healing across 19 study centres [23]. In this study, we report the cellular content (platelet, leukocyte and red cell counts), platelet quality and growth factor content of the L-PRP preparations prepared within all PATH-2 study sites. Few trials using PRP have reported platelet activation status or quality. It is important to demonstrate that PRP preparations are not activated prior to their injection/activation into the patient, as with activation they could degranulate and lose significant amounts of growth factors and biological activity. Together this provides a comprehensive study on the performance of a standardised preparation method and L-PRP device in pragmatic acute clinical settings within a multi-centre clinical trial. 


\section{Materials and Methods}

\section{PATH-2 Study}

PATH-2 was a multi-centre, parallel-group, participant and outcome assessor blinded randomised controlled trial comparing PRP to a placebo (imitation) injection[22]. The study was approved by the National Research Ethics Service Oxfordshire Committee A (reference 14/SC/1333) and overseen by an independent trial steering committee and data monitoring and ethics committee Participants were recruited in emergency department or at fracture clinic than allocated to treatments groups via a web based computer randomization system.

\section{Blood and PRP samples}

Venous blood $(\sim 5 \mathrm{ml})$ was taken from all trial participants and anticoagulated within EDTA vacutainers (Becton Dickinson, Plymouth, UK). For participants in the PRP group an additional $50 \mathrm{ml}$ of venous blood was drawn into a $60 \mathrm{ml}$ syringe that contained $8 \mathrm{ml}$ anticoagulant. The blood was drawn slowly to avoid platelet agitation and early activation. A $60 \mathrm{ml}$ syringe was fitted into the study specific centrifuge provided to all sites (MAG-200 MAGELLAN Autologous Platelet Separator, Arteriocyte Medical Systems). A sterile, disposable PRP kit (MDK 300/MDK 300-1 Platelet separation chamber, Arteriocyte Medical Systems) was placed in the centrifuge that was set to produce $8 \mathrm{ml}$ of sterile PRP, which was automatically fed into a $10 \mathrm{ml}$ syringe. $4 \mathrm{ml}$ was used for injection into the Achilles tendon and the remaining $4 \mathrm{ml}$ divided into $4 \mathrm{x} 1 \mathrm{ml}$ aliquots. All trial centres were trained how to use the device to prepare PRP and the samples for analysis before the trial commenced. One aliquot was used for cell counting and one aliquot was immediately frozen at $-70^{\circ} \mathrm{C}$ for storage until the end of the trial for batch measurement of growth factor levels (see below). The two remaining $1 \mathrm{ml}$ PRP aliquots were added to two vials (Platelet Solutions Ltd, Nottingham, UK) containing either saline alone to provide an unstimulated baseline or a combination of adenosine diphosphate and U46619 strong stimulation to fully activate/degranulate the platelets [24]. After 5 minutes, both samples were immediately fixed using $1 \mathrm{ml}$ PAMFix reagent (Platelet Solutions Ltd, Nottingham, UK). The whole blood, unfixed PRP and fixed PRP aliquots were held at room 
temperature until transported by courier to the Institute of Inflammation and Ageing at the University of Birmingham and processed as soon as possible after arrival.

\section{Cell Counting}

Whole blood and unfixed PRP cell counts were performed by using the Sysmex XN-1000 haematology analyser (Sysmex UK, Milton Keynes, UK). The analyser utilises three primary analysis principles; fluorescence flow cytometry, direct current (DC) detection with hydrodynamic focussing and SLS haemoglobin detection [25]. The WNR (white cell nucleated) channel evaluates white blood cell (WBC) count, basophils and nucleated red blood cells (RBC). An impedance RBC count is also reported. The WDF (white cell differential) channel also provides a differential count of the neutrophils, lymphocytes, eosinophils, monocytes and immature granulocytes (IG). The platelet fluorescence (PLT-F) channel is a specialised fluorescence-optical analysis exclusively for platelets. The PLT-F parameter utilises traditional fluorescence flow cytometry in which platelets are stained with oxazine; an RNA binding dye which eliminates any interference mediated by cellular debris. A measurement of platelet production (Immature Platelet Fraction) is also in this channel. The analyser thus reports three platelet counts: platelet impedance (PLT-I), platelet optical (PLTO) and PLT-F counts, mean platelet volume (MPV) and the immature platelet fraction (IPF). Quality control material (XN check, Sysmex UK, Milton Keynes, UK) was tested on a daily basis to ensure instrument performance throughout the study. The instrument was also enrolled into a national external quality assurance scheme (UKNEQAS, Watford, UK) and maintained on a service contract (Sysmex UK).

\section{Measurement of Platelet Quality}

Tubes containing either fixed resting or fully activated platelets respectively were analysed for the expression of a platelet specific degranulation/activation marker P-Selectin (CD62p) by flow cytometry as a measure of platelet quality. After gentle mixing $5 \mu$ of the fixed PRP was incubated with $5 \mu$ of test antibody (CD62p-FITC, Beckman Coulter, High Wycombe, Bucks) or its corresponding isotype control (IgG-FITC, Beckman Coulter) with $40 \mu \mathrm{l}$ of $0.2 \mu \mathrm{m}$ filtered Phosphate Buffered Saline ( $\mathrm{pH}$ 7.4) for 20 minutes at room temperature. The samples were then further diluted by addition of $4 \mathrm{ml}$ of PBS. The platelets were then analysed by flow 
cytometry (Accuri Flow cytometer, Becton Dickinson, Oxford, UK). Platelets were identified according to their characteristic size and granularity (using log forward scatter (FS) and log side scatter (SS)) with a FS threshold of 25,000 to eliminate noise/debris. An amorphous gate was placed around the platelet population and a total of 10,000 events collected. Analysis regions were set using the isotype control so that $0.5 \%$ of the platelet population were positive. CD62p positivity was then measured and both percentage expression and median fluorescent intensity (MFI) of all platelet events were recorded. The assay was validated prior to the trial by measuring both resting and activated platelet CD62p levels in normal control PRP volunteer samples prepared, processed and shipped under identical conditions.

\section{Measurement of Growth Factor levels within PRP}

At the end of patient recruitment, all frozen aliquots of PRP were shipped to Birmingham for analysis of growth factor levels. For analysis, samples were thawed at $37^{\circ} \mathrm{C}$ for 10 minutes. 1/40th volume of $20 \%$ Triton-X-100 was then added to ensure full cell lysis prior to a further incubation at $37^{\circ} \mathrm{C}$ for 10 minutes [26]. Samples were mixed and centrifuged at $1,500 \mathrm{~g}$ for 10 minutes at room temperature to remove insoluble debris. Supernatants were then removed and assayed for 5 different growth factors TGF- $\beta 1$, FGFb, VEGF, IGF-1 and PDGF-AB using commercial ELISA kits (Biotechne, Abingdon, Oxford, UK). Optimal sample dilutions for each growth factor were pre-determined by assaying L-PRP samples prepared from normal volunteers using an identical method of preparation. Diluted samples, blanks and standards were pipetted in duplicate into 96 well plates coated with capture antibodies and incubated as instructed within each growth factor ELISA kit. Plates were washed four times with the washing buffers and the peroxidase conjugated secondary antibodies provided within each kit, and added to each well and incubated as instructed. Plates were then washed four times with washing buffer before addition of substrate solution to each well. The plates were then incubated for 20-30 minutes at room temperature in the dark before addition of the stop solution. The optical density of each well was measured immediately using a microplate reader with readings performed at $450 \mathrm{~nm}$. A further reading was performed at $540 \mathrm{~nm}$ and the values subtracted from the readings at $450 \mathrm{~nm}$ to correct for optical imperfections in the plate. Duplicate readings were averaged for each standard, control and sample, and the zero standard optical density subtracted. Standard curves were generated by plotting the mean absorbance for each standard on the $\mathrm{y}$-axis against the concentration on the $\mathrm{x}$-axis and the best-fit line 
generated by regression analysis. Unknown sample values were read off the regression line and final concentrations determined by multiplying the dilution factors used in each assay. The concentration for each growth factor/ml of lysate was reported.

\section{Statistical Analysis}

All sub-study participants were included in descriptive analyses. Normally distributed data were summarised as means and standard deviations, and categorical variables as frequency and percentages. Details of the clinical trial statistical analysis are provided in the main study paper. [27].. A p-value of less than 0.05 was considered indicative of a statistically significant difference in all analyses. Analyses were conducted using Stata v15.0 (StataCorp, College Station, TX). 


\section{Results}

\section{PATH-2 Trial}

230 participants were recruited between July 2015 and September 2017 according to the trial design[22]. 114 were randomised to receive a single autologous PRP injection with 103 (90\% of target) receiving this treatment. 116 were allocated to, and received, placebo. For full details of the trial primary and secondary outcomes refer to the main study paper and monograph[27, 28].

\section{Cell Counts within whole blood and PRP}

Table 1 summarises all of the cell count and growth factor measurements within the L-PRP preparations in the PATH-2 trial. A comparison of the whole blood counts in the PRP test and placebo injection control groups is shown in Figure 1. There were no significant differences between RBC, platelet (PLT-F) count and WBC counts between each group. Figure 2 illustrates the blood cell counts within the L-PRP preparations showing the variation in PLTF, RBC and WBC counts. The mean platelet count (PLT-F) was 852.55 x 10\% $/ \mathrm{L}$ (SD 438.96) but with a wide range from 6 to $2903 \times 10^{9} / \mathrm{L}$. A small number of L-PRP platelet counts $(\mathrm{N}=$ 4) were lower than original whole blood counts due to unforeseen centrifuge device problems. As all the preparations were sent and measured in a central laboratory there was a time delay of the reporting of all blood and L-PRP cell counts during the trial. The 4 preparations with sub-optimal characteristics were therefore still used in the trial as cell counts were not immediately available. However, the trial was temporarily suspended after these products had been identified from their cell counts. After servicing performed by the manufacturer, the instruments were subsequently shown to be able to produce L-PRP before the trial re-started. Despite this the overall mean fold increase in platelets was a factor of 4.1. The mean RBC count was $0.91 \times 10^{12} / \mathrm{L}$ (SD 1.49) with a range from 0.14 to $8.98 \times 10^{12} / \mathrm{L}$. As expected the RBC count decreased on average in the PRP by a factor of 5.3 of the original count in whole blood. The mean WBC count was $15.13 \times 10^{9} / \mathrm{L}$ (SD 10.28) with a range of 1.68 to $65.29 \mathrm{x}$ 
$10^{9} / \mathrm{L}$. As this is an L-PRP preparation, as expected the WBC count increased by a factor of 2.2. The WBC differential count was $14.6 \%$ monocytes $\left(2.22 \times 10^{9} / \mathrm{L}\right.$, range 0 to 21.12$), 45.2 \%$ lymphocytes (6.84 x $10^{9} / \mathrm{L}$, range 0.07 to 18.72$), 39.2 \%$ neutrophils $\left(5.93 \times 10^{9} / \mathrm{L}\right.$ range 0.21 to 30.36$), 0.1 \%$ basophils $\left(0.02 \times 10^{9} / \mathrm{L}\right.$ range 0 to 0.52$)$ and $0.8 \%$ eosinophils $\left(0.13 \times 10^{9} / \mathrm{L}\right.$ range 0 to 1.46$)$.

\section{Platelet Quality}

The basal levels of CD62p expression (\% positivity and MFI) within the platelets of resting basal PRP $(\mathrm{N}=102)$ and activated PRP $(\mathrm{N}=103)$ samples are shown in Figure 3 . In resting basal PRP, the mean CD62p expression was 4.3\% (SD 5.05) with an MFI of 248.56 (SD 50.94). The majority of PRP samples were therefore of good quality with low levels of basal activation. In the activated PRP samples, the mean CD62p expression was 60.1\% (SD 22.26) with an MFI of 1208.05 (SD 556.60). The majority of PRP samples were therefore functional and capable of activation and degranulation.

\section{Growth factor levels within PRP}

The levels of each growth factor within the L-PRP preparations are shown in Figure 4. The mean concentrations of TGF- $\beta$, VEGF, PDGF, IGF and FGFb were 131.92 ng/ml (SD 74.37), $0.98 \mathrm{ng} / \mathrm{ml}$ (SD 0.72), $55.34 \mathrm{ng} / \mathrm{ml}$ (SD 27.64), $78.18 \mathrm{ng} / \mathrm{ml}$ (SD 23.18) and 111.04 pg/ml (SD 79.97) respectively. As expected there were some correlations between PLT-F count and WBC counts with growth factor levels. The PLT-F count correlated with VEGF $(r=0.454, p<0.001)$, PDGF $(r=0.704, p<0.001)$, FGF $(r=0.379, p<0.001)$ and TGF- $\beta(r=0.362, p<0.001)$ but not IGF $(r=0.061, p=0.550)$. The WBC count also correlated with VEGF $(r=0.734, p<$ 0.001), PDGF ( $r=0.487, \mathrm{p}<0.001)$, FGF $(\mathrm{r}=0.458, \mathrm{p}<0.001)$ and TGF- $\beta\left(\mathrm{r}^{2}=0.229, \mathrm{p}=\right.$ $0.025)$ but not IGF $(r=-0.130, p=0.194)$. 


\section{Discussion}

The PATH-2 study is, to our knowledge, the largest multicentre randomised controlled trial of a standardised L-PRP preparation within a musculoskeletal setting [22]. Although there was no significant effect of PRP injection on ATR healing when compared to placebo in terms of clinical outcomes [27], the trial also presented the opportunity to study in detail the performance of the Magellan device (Arteriocyte medical systems) within a large multicentre trial and the pragmatic application of standardised preparation protocol. The results of this substudy confirmed that the automated centrifuge method produced leukocyte-rich platelet rich plasma (L-PRP) with an average 4-fold increase of platelet concentration over the baseline whole blood platelet count. The leukocyte and RBC counts in the PRP were increased (factor of 2.2) or decreased (factor of 0.2) respectively compared to their baseline blood concentrations. The mean platelet count (PLT-F) was $852.55 \times 10^{9} / \mathrm{L}$ but with a wide range from 6 to $2903 \times 10^{9} / \mathrm{L}$. This equates to an average final dosage of 3.4 billion platelets equating to an overall high dosage using the DEPA classification system [12]. Table 2 compares the overall properties of the L-PRP using a number of different classification systems[7, 12, 16, 17]. As one might expect, the baseline whole blood parameters were similar in both groups prior to injection of PRP or placebo, as any variation in platelets and leukocytes in whole blood could have also impacted upon the healing process of tendons. Importantly, the average platelet, leukocyte and erythrocyte concentrations observed within the PRP preparations in PATH-2 were in the same order of magnitude as previously reported in a number of other studies and in line with manufacturer specifications using the Magellan device [29, 30].

As expected, there were also significant associations between the concentrations of TGF- $\beta 1$, PDGF-AB, VEGF and FGFb obtained within the PRP with both platelet and leukocyte counts. Importantly, the ranges of growth factor concentrations obtained were also comparable and within the same order of magnitude of previously reported levels in L-PRP prepared using the same device [31]. Remarkably, variations in L-PRP content (cell counts, growth factor content or platelet quality) were not associated with the level of recovery of Achilles tendon-muscle function (the primary trial outcome) [27]. Only VEGF gave a weak negative correlation with the primary outcome. Interestingly, a small number of participants also received very low concentrations of platelets and growth factors within their PRP due to a few unforeseen problems with the Magellan device, but this remarkably had no significant impact upon tendon healing compared to either the placebo or PRP groups[27]. The effects of the leukocytes 
(including neutrophils) and red cells in L-PRP for tendon healing are also uncertain, with in vitro investigations potentially identifying both a range of positive or negative effects [32-34]. Currently, leukocyte rich preparations are commonplace in clinical practice as buffy coat derived PRP results in significant leukocyte and red cell inclusion within L-PRP preparations. Future studies or trials comparing buffy coat derived L-PRP with PRP would help to fully resolve the impact of leukocytes on platelet mediated tendon healing. The results of this substudy therefore confirm that the majority of PATH-2 study participants randomised to PRP received an autologous supra-physiological preparation of L-PRP that was comparable to previous reports and the device manufacturer specifications. Technical issues or protocol variation may lead to altered cells or biological factors count as observed in 4 samples in this trial. Therefore, measuring the biological activity of PRP in clinical and research studies is crucial to ensure quality control and viability of the product. Furthermore, future studies of PRP in soft tissue healing should note the value of measuring the cellular and growth factor content of PRP preparations as a quality control of all the PRP preparations in order to confirm the quality and content of the product delivered to patients. 


\section{Acknowledgements}

The PATH-2 trial was funded by the Efficacy and Mechanism Evaluation programme, a Medical Research Council (MRC) and National Institute for Health Research (NIHR) partnership (reference 12/206/30). The trial was supported by the NIHR Biomedical Research Centre, Oxford, and the NIHR Fellowship programme (DJK, PDF-2016-09-056). SEL receives funding from the NIHR Collaboration for Leadership in Applied Health Research and Care Oxford at Oxford Health NHS Foundation Trust. University of Birmingham staff were funded by the Scar Free Foundation (SFF) and the NIHR Surgical Reconstruction and Microbiology Research Centre (SRMRC). The views and opinions expressed herein are those of the authors and do not necessarily reflect those of the MRC, NHS, SFF, NIHR, or Department of Health and Social Care. The sponsor (University of Oxford) and funders monitored the study but were not involved in the design and conduct of the study; collection, management, analysis, and interpretation of the data; preparation, review, or approval of the manuscript; and decision to submit the manuscript for publication.

\section{Disclosures}

We have no financial relationships with any organisations that might have an interest in the submitted work in the previous three years; SEL reports personal fees from Pleuristem, Israel, for consulting on the design of trials of stem cell interventions in hip fracture management and KW declares design royalties from Zimmer Biomet (Warsaw, IN, USA), for intramedullary bone fixation implants, outside the submitted work; KW held the role of medical director for acute care, NHS England, during the conduct of this study.

\section{Author Contributions}

JA, DJK, PHa, PHu, SJD, SEL, and KW contributed to the study concept and design. PHa. $\mathrm{MD}, \mathrm{AW}, \mathrm{AD}, \mathrm{RD}$ and JD all contributed to the laboratory analysis of PRP and blood samples. All the authors contributed to the acquisition, analysis, and interpretation of data. PHa, JA, DJK and KW drafted the manuscript. All the authors critically revised the manuscript for important intellectual content. HMO'C, MMS, SJD, SEL, JA and KW conducted the statistical 
analysis. DJK, JA, PHa, PHu, SJD, SEL, and KW obtained funding. SW, SRP, and JYT provided administrative and technical support. SEL and KW supervised the study. The corresponding author attests that all listed authors meet authorship criteria and that no others meeting the criteria have been omitted. DJK and $\mathrm{KW}$ act as guarantors and take responsibility for the integrity of the data and the accuracy of the data analysis. 


\section{Figure Legends}

Figure 1. Cell counts in whole blood samples by intervention group - Placebo and PRP, for (a) erythrocytes (x 10 $12 / \mathrm{L})$, (b) leukocytes (x 109/L), and (c) platelets (x 109/L).

Figure 2. : Cell counts in PRP samples, represented against the counts in whole blood samples, for (a) erythrocytes (x 10 $12 / \mathrm{L})$, (b) leukocytes (x 109/L), and (c) platelets (x 10 $/ \mathrm{L}$ ).

Figure 3. Measurement of platelet quality or degree of activation in the L-PRP samples, demonstrating (a) \% CD62p expression and (b) Mean Fluorescence Intensity (MFI) in activated and resting (unactivated) PRP.

Figure 4. Range of growth factor concentrations (ng/ml) in L-PRP preparations; FGFb, IGF1, PDGF-AB, TGF $\beta 1$ and VEGF. 


\section{Tables and Figures}

Table 1: Summary of L-PRP measurements prepared using the Magellan device: cell (platelets, leukocytes and erythrocytes) and growth factor (IGF-1, TGF $\beta 1$, PDGF-AB, VEGF and $\mathrm{FGFb}$ ) content.

\begin{tabular}{|c|c|c|c|c|c|c|c|c|}
\hline & $\begin{array}{l}\text { Platelets } \\
\left(\times 10^{9} / \mathrm{L}\right)\end{array}$ & $\begin{array}{l}\text { Leukocytes } \\
\left(\times 10^{9} / \mathrm{L}\right)\end{array}$ & $\begin{array}{l}\text { Erythrocytes } \\
\left(\times 10^{12} / \mathrm{L}\right)\end{array}$ & $\begin{array}{l}\text { IGF-1 } \\
\text { (ng/ml) }\end{array}$ & $\begin{array}{l}\text { TGF- } \beta 1 \\
\text { (ng/ml) }\end{array}$ & $\begin{array}{l}\text { PDGF- } \\
\text { AB } \\
\text { (ng/ml) }\end{array}$ & $\begin{array}{l}\text { VEGF } \\
\mathrm{ng} / \mathrm{ml})\end{array}$ & $\begin{array}{l}\text { FGF-b } \\
(\mathrm{pg} / \mathrm{ml})\end{array}$ \\
\hline $\mathbf{n}$ & 98 & 101 & 101 & 103 & 97 & 100 & 103 & 103 \\
\hline $\begin{array}{l}\text { Mean } \\
\text { (Standard } \\
\text { Error) }\end{array}$ & $852.55(44.34)$ & $15.13(1.02)$ & $0.91(0.15)$ & $\begin{array}{l}78.18 \\
(2.28)\end{array}$ & $\begin{array}{l}131.92 \\
(7.55)\end{array}$ & $\begin{array}{l}55.34 \\
(2.76)\end{array}$ & $\begin{array}{l}0.98 \\
(0.07)\end{array}$ & $\begin{array}{l}111.04 \\
(7.58)\end{array}$ \\
\hline $\begin{array}{l}\text { Standard } \\
\text { Deviation }\end{array}$ & 438.96 & 10.28 & 1.49 & 23.18 & 74.37 & 27.64 & 0.72 & 79.97 \\
\hline $95 \% \mathrm{Cl}$ & $\begin{array}{l}764.55- \\
949.56\end{array}$ & $13.10-17.16$ & $0.61-1.2$ & $\begin{array}{l}73.65- \\
82.71\end{array}$ & $\begin{array}{l}116.93- \\
146.90\end{array}$ & $\begin{array}{l}49.85- \\
60.82\end{array}$ & $\begin{array}{l}0.84- \\
1.12\end{array}$ & $\begin{array}{l}95.99- \\
126.08\end{array}$ \\
\hline Maximum & 2903 & 65.29 & 8.98 & 158.04 & 320.93 & 151.30 & 4.34 & 368.55 \\
\hline Minimum & 6 & 1.68 & 0.14 & 28.85 & 0 & 0 & 0 & 0 \\
\hline Range & 2897 & 63.61 & 8.84 & 129.19 & 320.93 & 151.30 & 4.34 & 368.55 \\
\hline
\end{tabular}




\begin{tabular}{|c|c|}
\hline $\begin{array}{l}\text { PRP Classification } \\
\text { System }\end{array}$ & Parameters \\
\hline PAW & $\begin{array}{l}\text { P3Aa (i.e. platelet count } 852.6 \times 10^{3} / \mathrm{ml} \text {, leukocytes and neutrophils } \\
\text { above baseline and activated with calcium chloride }\end{array}$ \\
\hline PRLA & $\begin{array}{l}4 \mathrm{ml} \text { of L-PRP containing platelets } 852.6 \times 10^{3} / \mathrm{ml},+ \text { white cells }(< \\
1 \%) 15.13 \times 10^{3} / \mathrm{ml}, 39 \% \text { neutrophils }+ \text { RBC }(>1 \%) 907 \times 10^{3} / \mathrm{ml}, \\
\text { activated with calcium chloride }\end{array}$ \\
\hline DEPA & $\begin{array}{l}\left.\text { Dose - B (High Dose, } 3.4 \times 10^{12}\right), \text { Recovery Efficiency - C (Low, } \\
54.6 \%) \text {, Purity - C (Heterogeneous, } 48 \%) \text {, activated with calcium } \\
\text { chloride }\end{array}$ \\
\hline ISTH SSC & $\begin{array}{l}\text { Red-L-PRP IIA1 (i.e. a Red blood/leukocyte cell rich PRP } \\
\text { containing a platelet count }<900 \times 10^{9} / \mathrm{L} \text { and was prepared by } \\
\text { Gravitational centrifugation, activated with calcium chloride }\end{array}$ \\
\hline
\end{tabular}

Table 2. Classification of the L-PRP preparations in the PATH-2 trial using 4 different classification Systems : 1) PAW [16]; 2) PLRA[17] ; 3) DEPA[12] and 4) ISTH SSC[7] from the mean values of platelets, leukocytes and red cells in the autologous L-PRP compared to the original whole blood. 
(a)

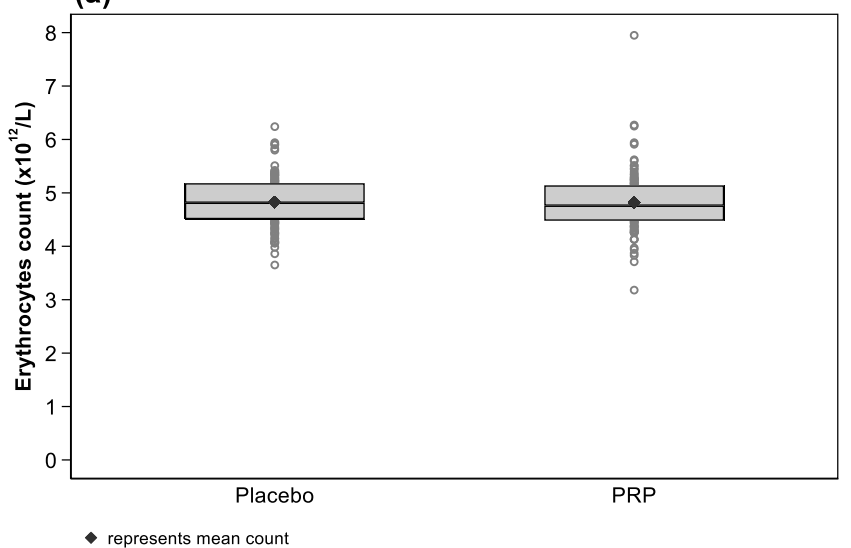

(b)

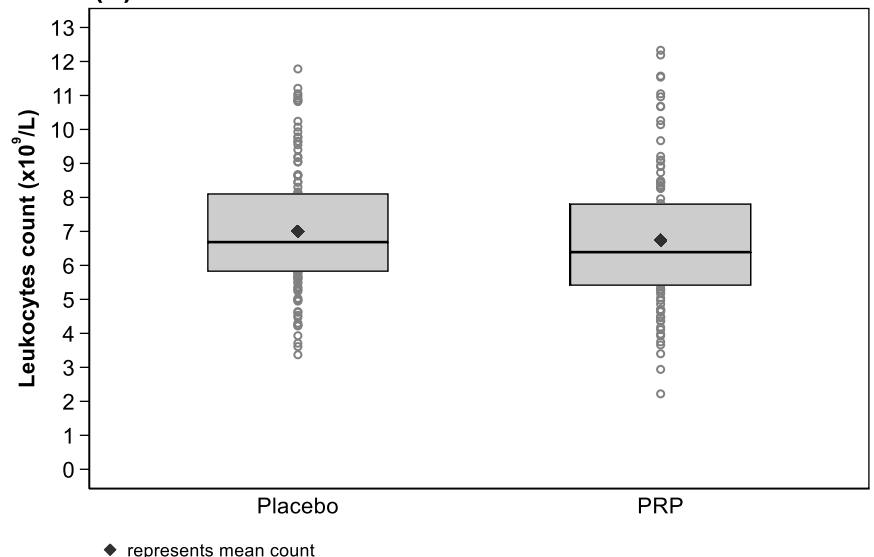

(c)

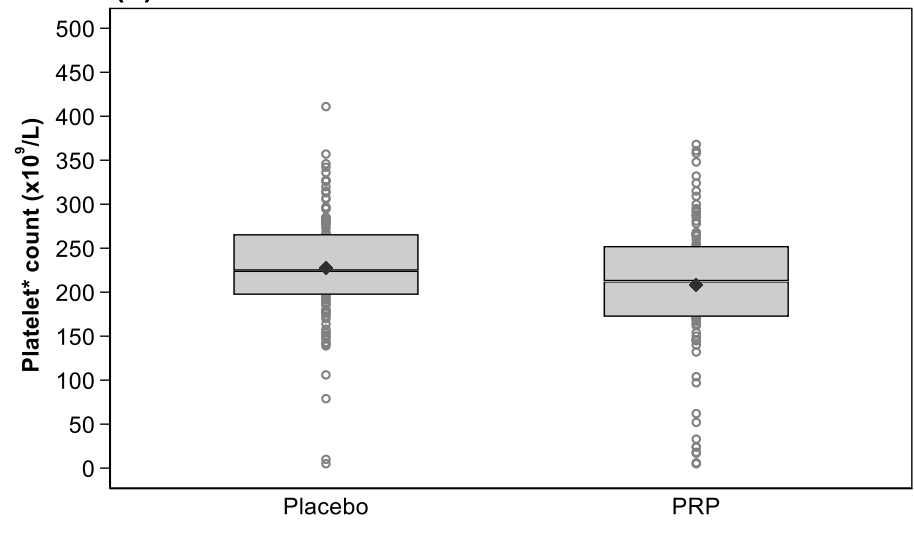

- represents mean count

* using PLT-F measure

Figure 1. 
(a)

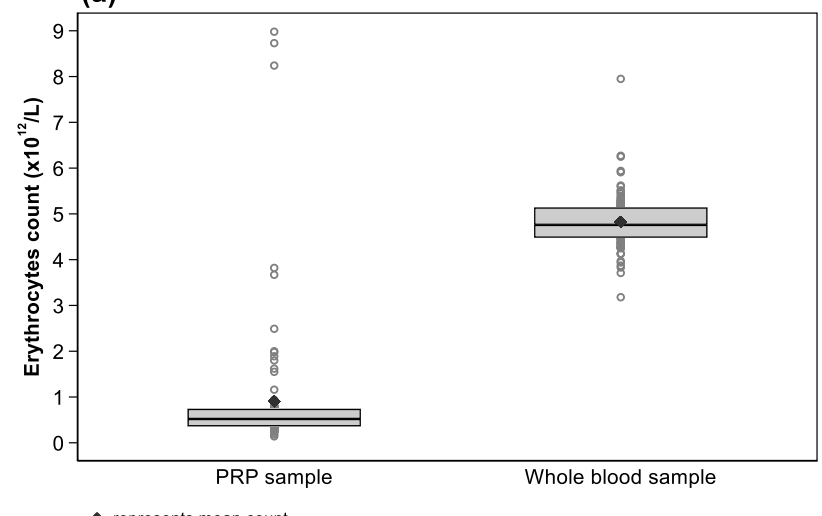

(b)

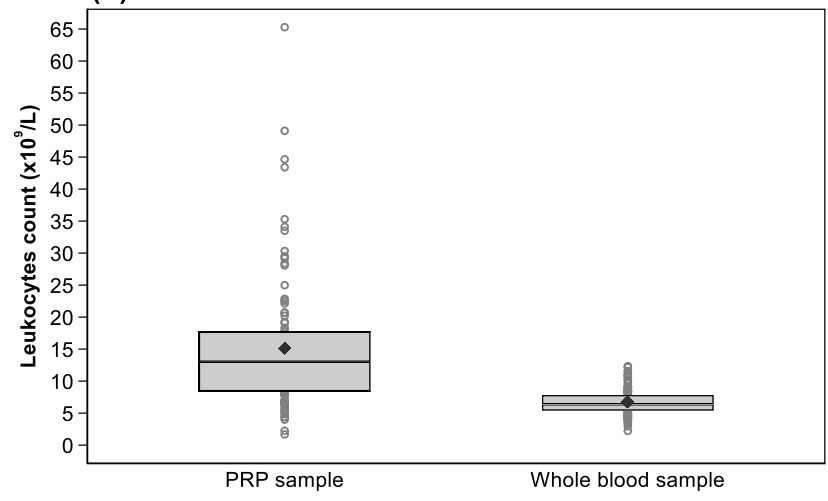

- represents mean count

(c)

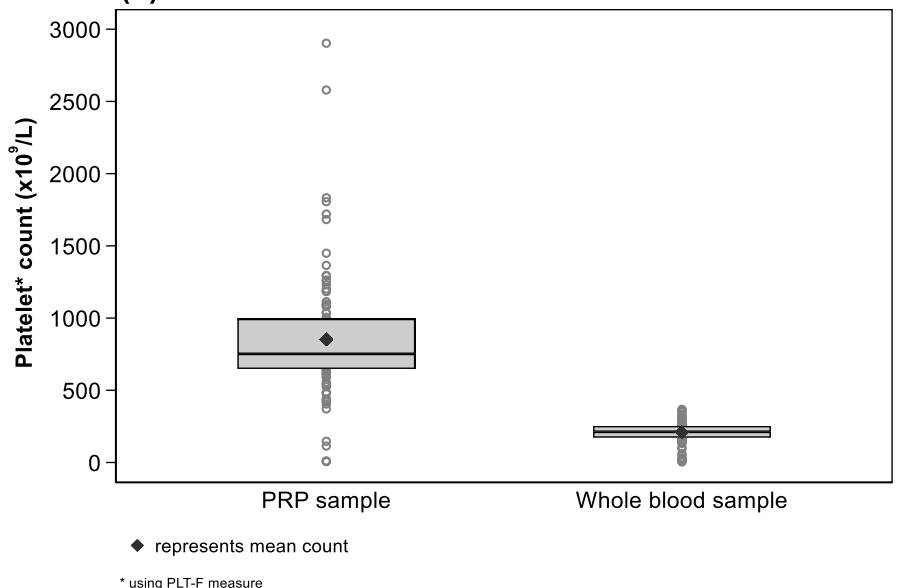

Figure 2. 
(a)

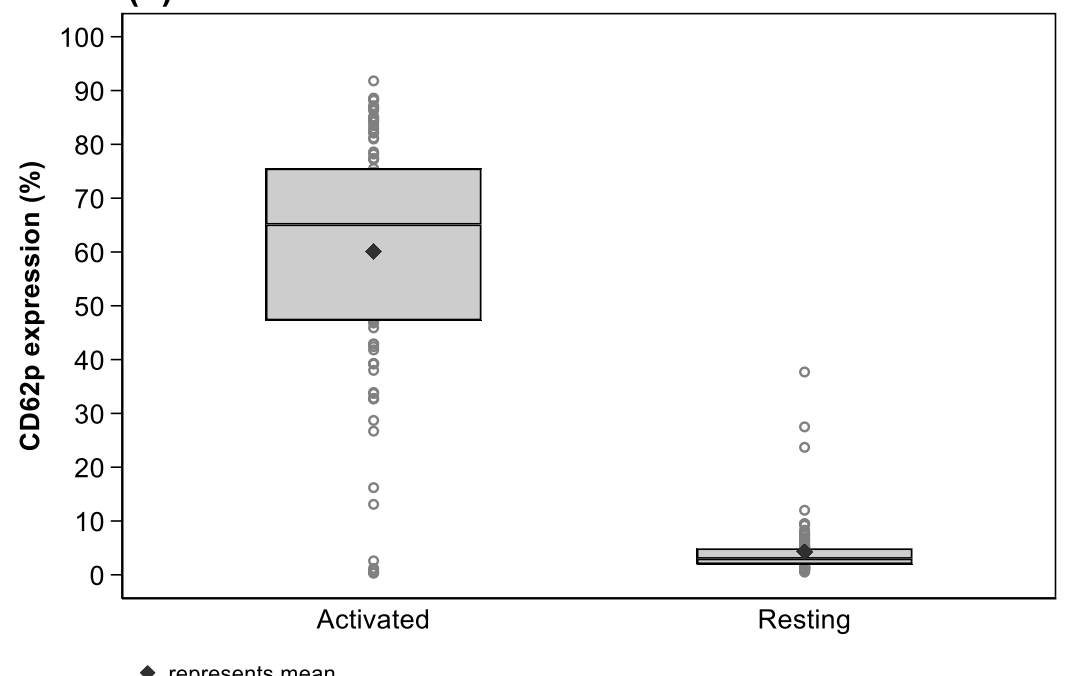

(b)

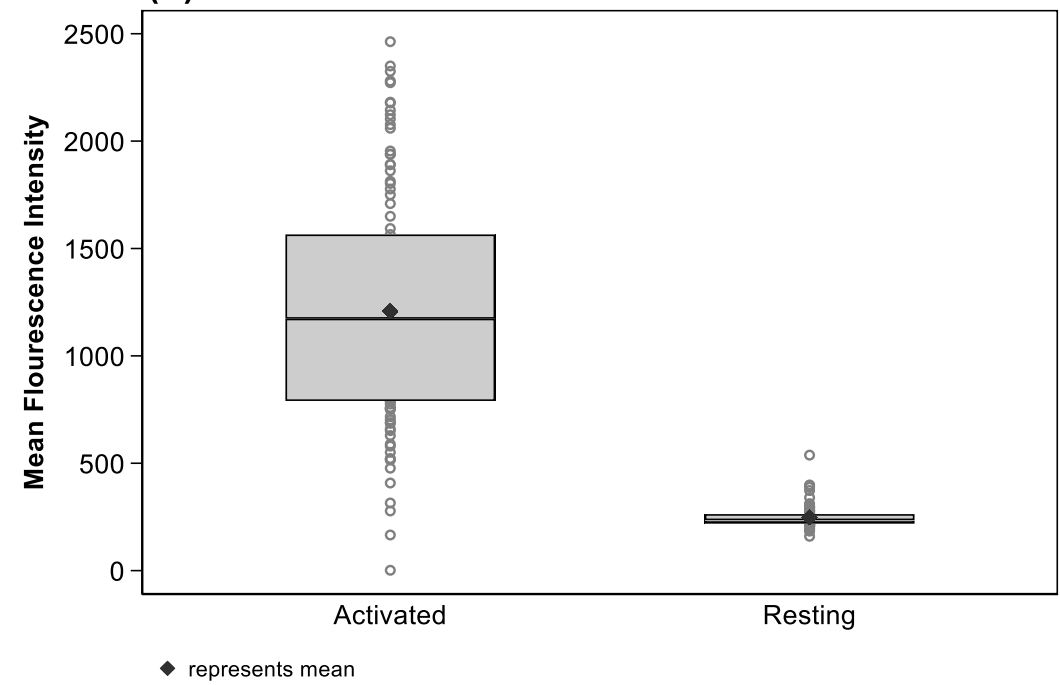

Figure 3. 


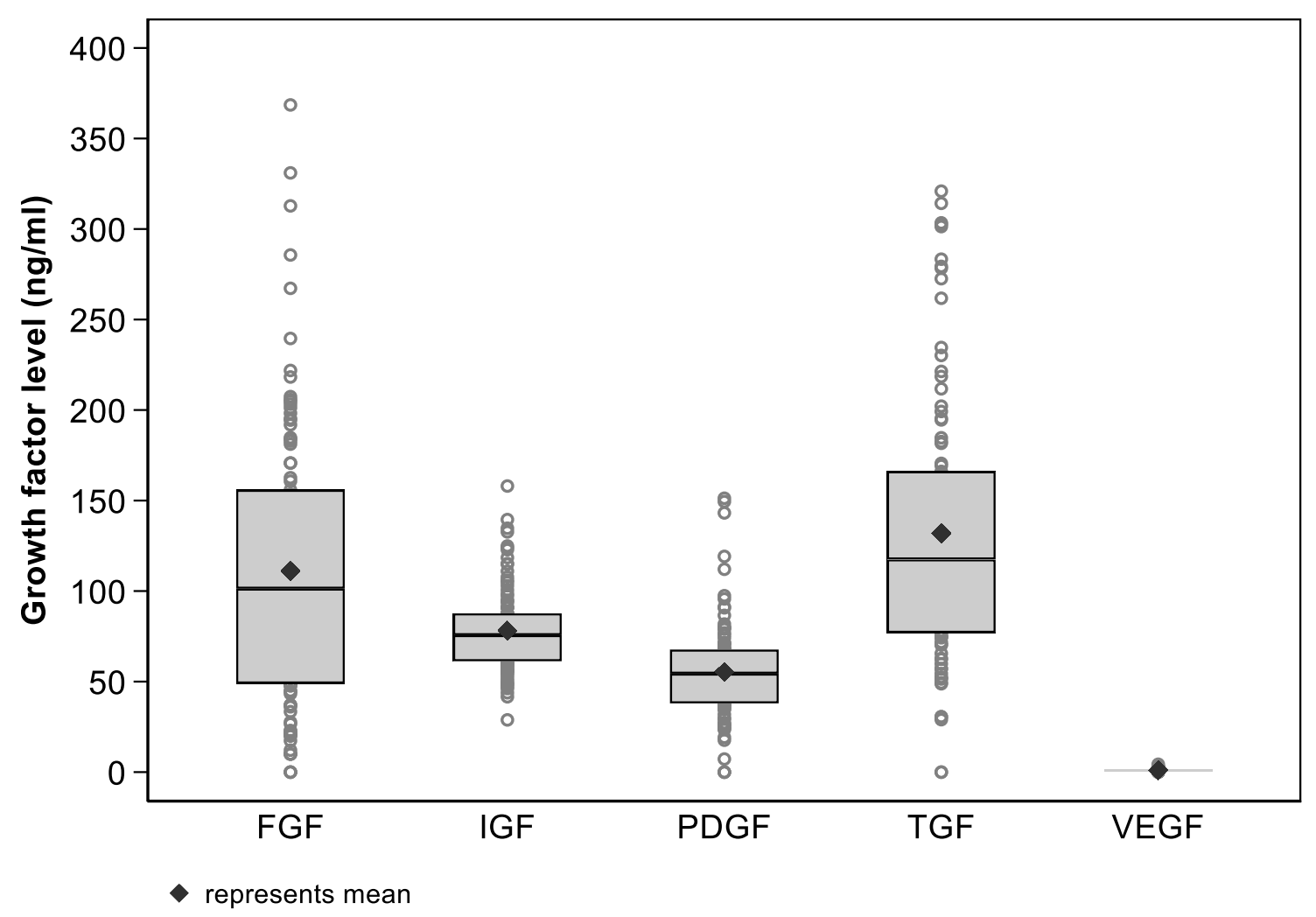

Figure 4 


\section{References}

1. Nurden, A. T. (2011) Platelets, inflammation and tissue regeneration. Thromb Haemost 105 Suppl 1, S13-33.

2. Rachul, C., Rasko, J. E. J., Caulfield, T. (2017) Implicit hype? Representations of platelet rich plasma in the news media. PLoS One 12, e0182496.

3. Alsousou, J. and Harrison, P. (2017) Platelet-Rich Plasma in Regenerative Medicine. In Platelets in Thrombotic and Non-Thrombotic Disorders (K. N. Gresele P., Lopez J., Page C. , ed) Springer, Cham.

4. Alsousou, J., Ali, A., Willett, K., Harrison, P. (2013) The role of platelet-rich plasma in tissue regeneration. Platelets 24, 173-82.

5. Alves, R. and Grimalt, R. (2018) A Review of Platelet-Rich Plasma: History, Biology, Mechanism of Action, and Classification. Skin Appendage Disord 4, 18-24.

6. Anitua, E., Andia, I., Ardanza, B., Nurden, P., Nurden, A. T. (2004) Autologous platelets as a source of proteins for healing and tissue regeneration. Thromb Haemost 91, 4-15.

7. Harrison, P. and Subcommittee on Platelet, P. (2018) The use of platelets in regenerative medicine and proposal for a new classification system: guidance from the SSC of the ISTH. J Thromb Haemost 16, 1895-1900.

8. Moreno, R., Gaspar Carreno, M., Alonso Herreros, J. M., Romero Garrido, J. A., Lopez-Sanchez, P. (2016) [Platelet-rich plasma: updating of extraction devices]. Farm Hosp 40, 385-93.

9. de Melo, B. A. G., Martins Shimojo, A. A., Marcelino Perez, A. G., Duarte Lana, J. F. S., Andrade Santana, M. H. (2017) Distribution, recovery and concentration of platelets and leukocytes in L-PRP prepared by centrifugation. Colloids Surf B Biointerfaces 161, 288-295.

10. Sharma, N. K. (2018) Platelet-rich fibrin: Emerging biomaterial in regeneration. Natl J Maxillofac Surg 9, 1.

11. Dohan Ehrenfest, D. M., Rasmusson, L., Albrektsson, T. (2009) Classification of platelet concentrates: from pure platelet-rich plasma (P-PRP) to leucocyte- and platelet-rich fibrin (LPRF). Trends Biotechnol 27, 158-67.

12. Magalon, J., Chateau, A. L., Bertrand, B., Louis, M. L., Silvestre, A., Giraudo, L., Veran, J., Sabatier, F. (2016) DEPA classification: a proposal for standardising PRP use and a retrospective application of available devices. BMJ Open Sport Exerc Med 2, e000060.

13. Chahla, J., Cinque, M. E., Piuzzi, N. S., Mannava, S., Geeslin, A. G., Murray, I. R., Dornan, G. J., Muschler, G. F., LaPrade, R. F. (2017) A Call for Standardization in Platelet-Rich Plasma Preparation Protocols and Composition Reporting: A Systematic Review of the Clinical Orthopaedic Literature. J Bone Joint Surg Am 99, 1769-1779.

14. Marques, L. F., Stessuk, T., Camargo, I. C., Sabeh Junior, N., dos Santos, L., Ribeiro-Paes, J. T. (2015) Platelet-rich plasma (PRP): methodological aspects and clinical applications. Platelets 26, 101-13.

15. Murray, I. R., Geeslin, A. G., Goudie, E. B., Petrigliano, F. A., LaPrade, R. F. (2017) Minimum Information for Studies Evaluating Biologics in Orthopaedics (MIBO): Platelet-Rich Plasma and Mesenchymal Stem Cells. J Bone Joint Surg Am 99, 809-819.

16. DeLong, J. M., Russell, R. P., Mazzocca, A. D. (2012) Platelet-rich plasma: the PAW classification system. Arthroscopy 28, 998-1009.

17. Mautner, K., Malanga, G. A., Smith, J., Shiple, B., Ibrahim, V., Sampson, S., Bowen, J. E. (2015) A call for a standard classification system for future biologic research: the rationale for new PRP nomenclature. PM R 7, S53-9.

18. Oda, H., Sano, K., Kunimasa, Y., Komi, P. V., Ishikawa, M. (2017) Neuromechanical Modulation of the Achilles Tendon During Bilateral Hopping in Patients with Unilateral Achilles Tendon Rupture, Over 1 Year After Surgical Repair. Sports Med 47, 1221-1230. 
19. Maffulli, N., Longo, U. G., Maffulli, G. D., Rabitti, C., Khanna, A., Denaro, V. (2011) Marked pathological changes proximal and distal to the site of rupture in acute Achilles tendon ruptures. Knee Surg Sports Traumatol Arthrosc 19, 680-7.

20. De Carli, A., Lanzetti, R. M., Ciompi, A., Lupariello, D., Vadala, A., Argento, G., Ferretti, A., Vulpiani, M. C., Vetrano, M. (2016) Can platelet-rich plasma have a role in Achilles tendon surgical repair? Knee Surg Sports Traumatol Arthrosc 24, 2231-7.

21. Alsousou, J., Thompson, M., Harrison, P., Willett, K., Franklin, S. (2015) Effect of platelet-rich plasma on healing tissues in acute ruptured Achilles tendon: a human immunohistochemistry study. Lancet 385 Suppl 1, S19.

22. Alsousou, J., Keene, D. J., Hulley, P. A., Harrison, P., Wagland, S., Byrne, C., Schlussel, M. M., Dutton, S. J., Lamb, S. E., Willett, K. (2017) Platelet rich Plasma in Achilles Tendon Healing 2 (PATH-2) trial: protocol for a multicentre, participant and assessor-blinded, parallel-group randomised clinical trial comparing platelet-rich plasma (PRP) injection versus placebo injection for Achilles tendon rupture. BMJ Open 7, e018135.

23. Degen, R. M., Bernard, J. A., Oliver, K. S., Dines, J. S. (2017) Commercial Separation Systems Designed for Preparation of Platelet-Rich Plasma Yield Differences in Cellular Composition. HSS J 13, 75-80.

24. Dovlatova, N., Lordkipanidze, M., Lowe, G. C., Dawood, B., May, J., Heptinstall, S., Watson, S. P., Fox, S. C., Group, U. G. S. (2014) Evaluation of a whole blood remote platelet function test for the diagnosis of mild bleeding disorders. J Thromb Haemost 12, 660-5.

25. Briggs, C., Longair, I., Kumar, P., Singh, D., Machin, S. J. (2012) Performance evaluation of the Sysmex haematology XN modular system. J Clin Pathol 65, 1024-30.

26. Harrison, P., Wilbourn, B., Debili, N., Vainchenker, W., Breton-Gorius, J., Lawrie, A. S., Masse, J. M., Savidge, G. F., Cramer, E. M. (1989) Uptake of plasma fibrinogen into the alpha granules of human megakaryocytes and platelets. J Clin Invest 84, 1320-4.

27. Keene, D. J., Alsousou, J., Harrison, P., Hulley, P., Wagland, S., Parsons, S. R., Thompson, J. Y., O'Connor, H. M., Schlussel, M. M., Dutton, S. J., Lamb, S. E., Willett, K., group, P.-t. (2019) Platelet rich plasma injection for acute Achilles tendon rupture: PATH-2 randomised, placebo controlled, superiority trial. BMJ 367, 16132.

28. Alsousou, J., Keene, D. J., Harrison, P., Hulley, P., Wagland, S., Thompson, J. Y., Parsons, S. R., Byrne, C., Schlussel, M. M., O'Connor, H. M., Dutton, S. J., Lamb, S. E., Willett, K. (2019) In Platelet-rich plasma injection for adults with acute Achilles tendon rupture: the PATH-2 RCT, Southampton (UK).

29. Kushida, S., Kakudo, N., Morimoto, N., Hara, T., Ogawa, T., Mitsui, T., Kusumoto, K. (2014) Platelet and growth factor concentrations in activated platelet-rich plasma: a comparison of seven commercial separation systems. J Artif Organs 17, 186-92.

30. Castillo, T. N., Pouliot, M. A., Kim, H. J., Dragoo, J. L. (2011) Comparison of growth factor and platelet concentration from commercial platelet-rich plasma separation systems. Am J Sports Med 39, 266-71.

31. Patel, A. N., Selzman, C. H., Kumpati, G. S., McKellar, S. H., Bull, D. A. (2016) Evaluation of autologous platelet rich plasma for cardiac surgery: outcome analysis of 2000 patients. J Cardiothorac Surg 11, 62.

32. Zhou, Y., Zhang, J., Wu, H., Hogan, M. V., Wang, J. H. (2015) The differential effects of leukocyte-containing and pure platelet-rich plasma (PRP) on tendon stem/progenitor cells implications of PRP application for the clinical treatment of tendon injuries. Stem Cell Res Ther 6, 173.

33. Everts, P. A., Malanga, G. A., Paul, R. V., Rothenberg, J. B., Stephens, N., Mautner, K. R. (2019) Assessing clinical implications and perspectives of the pathophysiological effects of erythrocytes and plasma free hemoglobin in autologous biologics for use in musculoskeletal regenerative medicine therapies. A review. Regen Ther 11, 56-64. 
34. Oudelaar, B. W., Peerbooms, J. C., Huis In 't Veld, R., Vochteloo, A. J. H. (2019) Concentrations of Blood Components in Commercial Platelet-Rich Plasma Separation Systems: A Review of the Literature. Am J Sports Med 47, 479-487. 